\title{
An Academic Portal for Higher Education Information Literacy: the e-COMS initiative
}

Maria Pinto, Professor, Department of Information Science, University of Granada, Spain.

A.-Vinciane Doucet, Scholarship Holder Department of Information Science, University of Granada, Spain.

Correspondence to: Maria Pinto, Department of Information Science, University of Granada, Spain. E-mail: mpinto@ugr.es

\section{Introduction}

A modern society need a modern higher education system with special emphasis on knowledge management, information technologies and lifelong learning. In this context, the creation of a knowledgebased Europe is a source of opportunities and challenges for higher education institutions in the pursuit of a more competitive, dynamic and flexible society [1]. Here, universities have a major role to play as research and teaching centers for the training and preparation of citizens for the $21^{\text {st }}$ century, taking on the responsibility to face the changes consequent to the introduction of the European Higher Education Area (EHEA), as set out in the Sorbonne Declaration and other previous declarations. The European Union needs a healthy, flourishing university environment in which the excellence of its universities can be furthered and the objective established in the Declaration of Graz [2] can be achieved: to become the most competitive and dynamic knowledge-based economy in the world, capable of sustainable economic growth with more and better jobs and greater social cohesion. Likewise, in light of the demands of electronic learning, universities will need to embrace all the potential offered by information and communication technologies as tools to improve access to education and as a guarantee of quality in learning.

On this road towards European convergence, Spanish universities are facing major changes associated with modifications to degree and curriculum formats, with the increasing proliferation of educational information and communication technology platforms, and with the application of the European Credit Transfer and Accumulation System (ECTS). The latter not only involves changes in teaching and learning methods, but also affects information centers, libraries, and learning and research resource centers. Within 
this framework, university students need to acquire sufficient training in the use of information skills and competencies as a way of fostering an autonomous, reflexive learning process; they need to become familiar with every aspect of information and knowledge, from its generation, organization, analysis and synthesis, to its evaluation, management and use, in order to be capable of integrating and using it to create new knowledge.

\section{New needs and challenges in the knowledge age}

\subsection{Information literacy as a context for lifelong learning}

In general, documentation models are found in the guidelines of international library associations such as ACRL [3], CAUL [4], IFLA [5], which advocate instruction in the skills of information search, analysis, evaluation, use, sharing and diffusion in an ethical way, regardless of typology, content or organizational method. Two statements from UNESCO also complement this point: the first on the need for lifelong learning, enabling the individual learner to learn in order to solve problems [6]; and the second, the World Declaration on Higher Education, which proposes a new student-based educational model in which the student must acquire a critical spirit to analyze problems, knowing how to adopt solutions, and assuming social responsibilities. We completely agree with statements from the Spanish University Rectors' Conference Report 2000 and from the Commission of the European Communities [1] that highlight the importance of adopting innovative teaching strategies to capture students' attention; of modifying teaching methods to focus on student self-learning, and skill and ability acquisition.

From our own teaching experience, and endorsed by recent research, we know that the profile of the Spanish university student has changed over recent years [7]. People are considered to be information literate when they know when and why they need information, where to find it and how to evaluate, use and communicate it ethically [8]. These premises take us to the heart of information literacy, understood as the set of aptitudes that refer to the use and command of information in any of the forms it takes, and of the technologies that provide access to that information. As Dewald, Scholz-Crane, Booth, and Levine [9] state, information literacy is an essential component of the education process, at all levels from basic to advanced, by which the student learns to learn actively and to think critically and autonomously. Moreover, the development of digital literacy and its main exponent, the Internet, enables intelligent people to connect, thereby generating and sharing new knowledge and experiences.

According to Koh [10], sometimes students may ask a librarian to find the educational materials they need, preferring to use telephone or virtual services themselves. The task of helping students to become information literate should be integrated and shared by professors and librarians; a unified and coherent effort is essential if students are to emerge with knowledge in their disciplines and the skills and competencies to approach problem solving throughout their lives [11]. 


\subsection{The challenge of lifelong learning: competency training}

Only by organizing a European Higher Education Area (EHEA) in accordance with principles of quality, mobility, diversity and competition, and by being constantly mindful that higher education is at the crossroads of research, education and innovation, will we be able to move towards achieving the strategic objectives for Europe. Some countries, such as the United Kingdom and the Republic of Ireland, were further forward in the development of "new learning".

In the nineteen nineties certain improvements were introduced into the Spanish university system. These included pedagogical training programs for teaching staff run by the Educational Sciences Institutes (Institutos de Ciencias de la Educación), improved teaching staff-student ratios, and above all, the adaptation of curricula to new employment demands, especially in practical placements. The process of institutional evaluation of degrees, departments and services was also instigated to provide a diagnosis of the situation in Spanish universities and to detect weaknesses in order to define plans for real improvements. More than ever before, the Spanish university system should:

- $\quad$ provide comprehensive information literacy instruction of the highest order

- $\quad$ be open and accessible to all students

- $\quad$ spread knowledge on both content (knowing), and procedures and methodologies (know-how)

- $\quad$ actively assert that the greatest change in our society will be in knowledge, in its form and content, meaning and responsibility, and in what it means to be a competent person [12]

One of the essential contributions made by the Bologna process was to situate the concept of competencies at the center of university student instruction and higher education. Some authors assume that competencies are theoretical constructs and hypothetical psychological processes that include groups of cognitive, emotional, motivational, social and behavioral components [13].

Delors propose the next key competencies:

- $\quad$ Learning to be, how to act with personal autonomy, judgment and responsibility.

- Learning to know, combining a broad general education with the possibility for in-depth study of certain subjects; and learning to learn in order to continue learning throughout life.

- $\quad$ Learning to do, knowing how to face up to a wide variety of situations.

- $\quad$ Learning to live and work together, through better knowledge and understanding of others, the world and its interrelations.

From the DESECO and TUNING projects, three types of competencies can be defined [14]:

- GENERIC or transversal competencies: communication, problem-solving, reasoning, leadership capacity, creativity, motivation, teamwork and in particular, learning ability.

- BASIC competencies: reading, writing, calculation, information technology, foreign languages, technological culture etc. 
- SPECIFIC competencies; these are specific to the degree, specialization and employment profile the student is preparing for.

\section{3. $\quad$ The need for blended learning}

The change in learning organization, which implies the shift from a teaching-centered to a learningcentered education, involves a new focus in the role of the educator and educational activities, and places greater emphasis on the results of learning. In line with this learning model, we promote the combined use of classroom-based and distance education strategies through the development of academic portals that provide universal access to contents and information (open access resources) that the university community find manageable, understandable and credible. We consider educational web resources to provide a useful alternative support for student learning [15]. Lewis and Orton point out that the web offers students multiple ways of accessing specific knowledge content at their own pace and through their own choices.

Web-based learning offers the chance to cultivate demand for student-centered instruction. However, successful implementation to create a distributed and meaningful learning environment requires the systematic understanding of various factors. Khan [16] suggests a framework for web-based learning that contains the following dimensions: pedagogical, technological, interface design, evaluation, management, resources support, ethical, and institutional aspects. Each dimension has several items focused on a specific aspect of web-based learning.

\section{The e-Learning Portal as a Quality Learning Resource}

A learning portal may be defined as a single integrated point providing useful and comprehensive access to information and, in addition to content, it also offers information, data search tools, didactic resources, interactive teaching material, interpersonal communication tools, training, assessment, etc. [17]. Besides acting as a gateway and a content organizer, portals provide access to quality information and learning resources (experts, teachers, researchers), encourage interaction with those resources and with other students, and support new models of teaching, learning and research [18]. Batson [19] suggests that a learning portal expands on traditional academic space by eliminating physical boundaries, and performs an important socialization function for both learners and teachers. The nature of teaching and learning is defined as a landscape in which learning events are structured by place, time and format. Looney \& Lyman [20] consider portals to be an outstanding tool for the user in that they provide a wide variety of useful resources, enabling the user to personalize information, by selecting and viewing only the information he or she is interested in. Boettcher sees a content portal as a gateway to web access where users can locate the web content they need.

A content portal differs from other initiatives such as homepages or information.com sites in that it focuses on the user and not on the owner. Its designers are fully aware of the information needs of its end user, and the portal also has the additional advantage that it allows for personalization. These aspects endorse the further 
creation of scholars portals, despite the complexity and expense involved in this task, which requires a combined effort across the university community (librarians, academics, students, etc.).

These are the main aspects of an e-learning portal [21, 22]:

- $\quad$ Content: by promoting innovation, providing access to the highest quality content on the web and fostering the use of standards, database searches and support tools. The use of interactive content maps is recommended to provide simple viewing of significant information.

- $\quad$ Enhanced services, such as varied information, news, reports, bibliographic notifications, to promote access to use of the complete text, the provision of specialized materials, shared work spaces and support tools for scientific publishing.

- Quality engines and tools that act as a user guide to the portal, from search engines, advanced retrieval methods, tutorials, electronic thesauri, email, forums, chat rooms etc.

- $\quad$ FAQs may be aimed at a specific group or designed as online help or computer-based instruction for our applications.

- $\quad$ Access to resources, particularly to the applications software used on a daily basis at work

- $\quad$ Portal updating through accurate and relevant content management according to user needs.

We believe the decision to implement an academic portal to enhance learning opportunities must take into account not only the institution's educational goals and strategies, and financial cost, but must also address issues of access, flexibility, innovation, personalization, credibility, quality and transparency of information [18].

\section{Design of the e-COMS learning portal for Information Literacy}

A SWOT analysis of this first-hand information followed by focus group discussion with colleagues led a group of academic experts from various Spanish universities to take on the development of this elearning portal. The e-COMS portal is generic and transversal, and is valid for all university students who need to acquire skills and training in information literacy, particularly in relation to the management of elearning content. This initiative is a pioneer project in the field of library science and documentation in Spain, and is aligned with the commitment of the Spanish University Library Network (Red Española de Bibliotecas Universitarias) [23] to promote the creation and integration of useful teaching materials, to promote information literacy in students, and to participate in autonomous learning. This is the philosophy behind the design of the e-COMS academic portal, freely available at: http://www.mariapinto.es/e-coms

The design of the portal was grounded in recent research into the implementation of scholar and elearning portals [24], and followed this action plan (Fih.1):

Conceptual design: included the development of a brief white paper to define the conceptual, functional and technical requirements of the e-COMS portal. 
Technical design: the conceptual solutions and modifications identified in the brainstorming sessions were used to approach the technical design of the educational portal environment.

Development of the e-COMS prototype: this included the construction of a small-scale educational portal.

Prototype testing: a test was designed to evaluate the functional usability of the system. A pilot study was run on a sample of Humanities students from the universities of Granada and Malaga who evaluated its usability.

Implementation of e-COMS: this included the development of the final portal to establish categories, define support groups and the responsibilities assigned to each team member.

Portal system upgrade: six-monthly upgrades were set to review content and to incorporate new applications, tools and services.

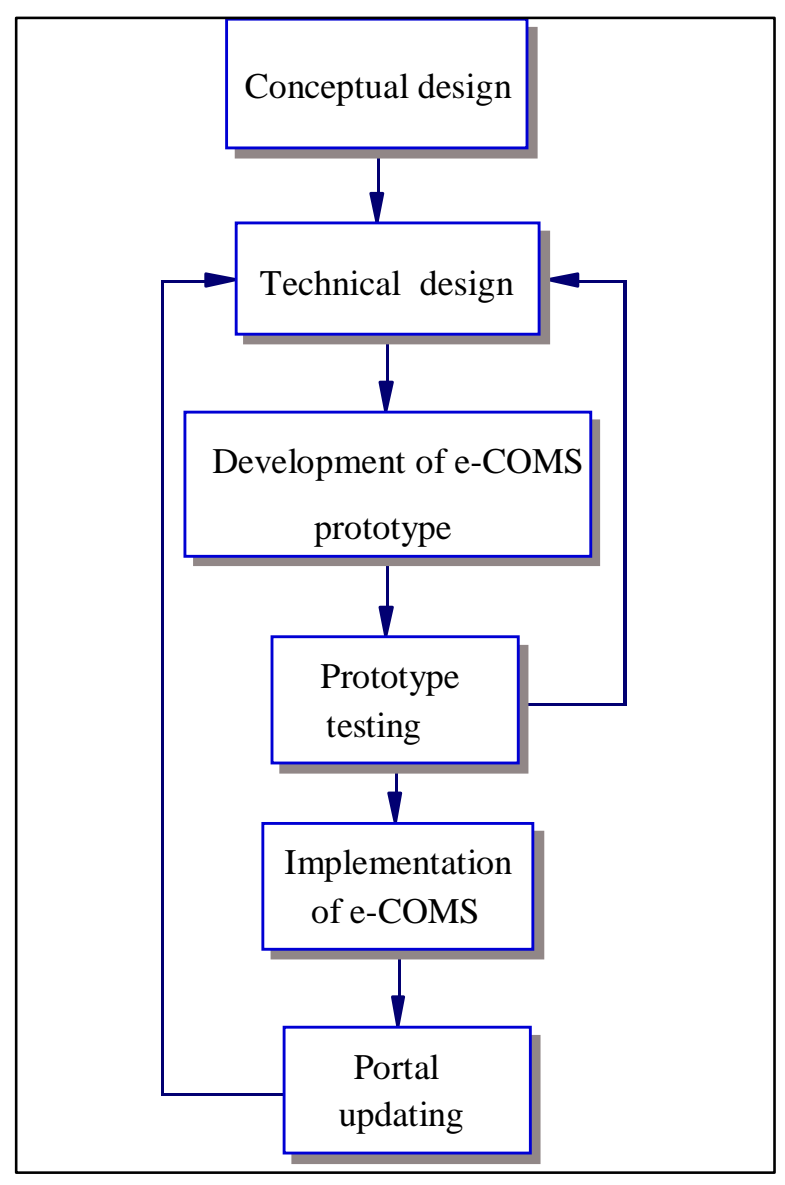

Figure 1. e-COMS action plan 


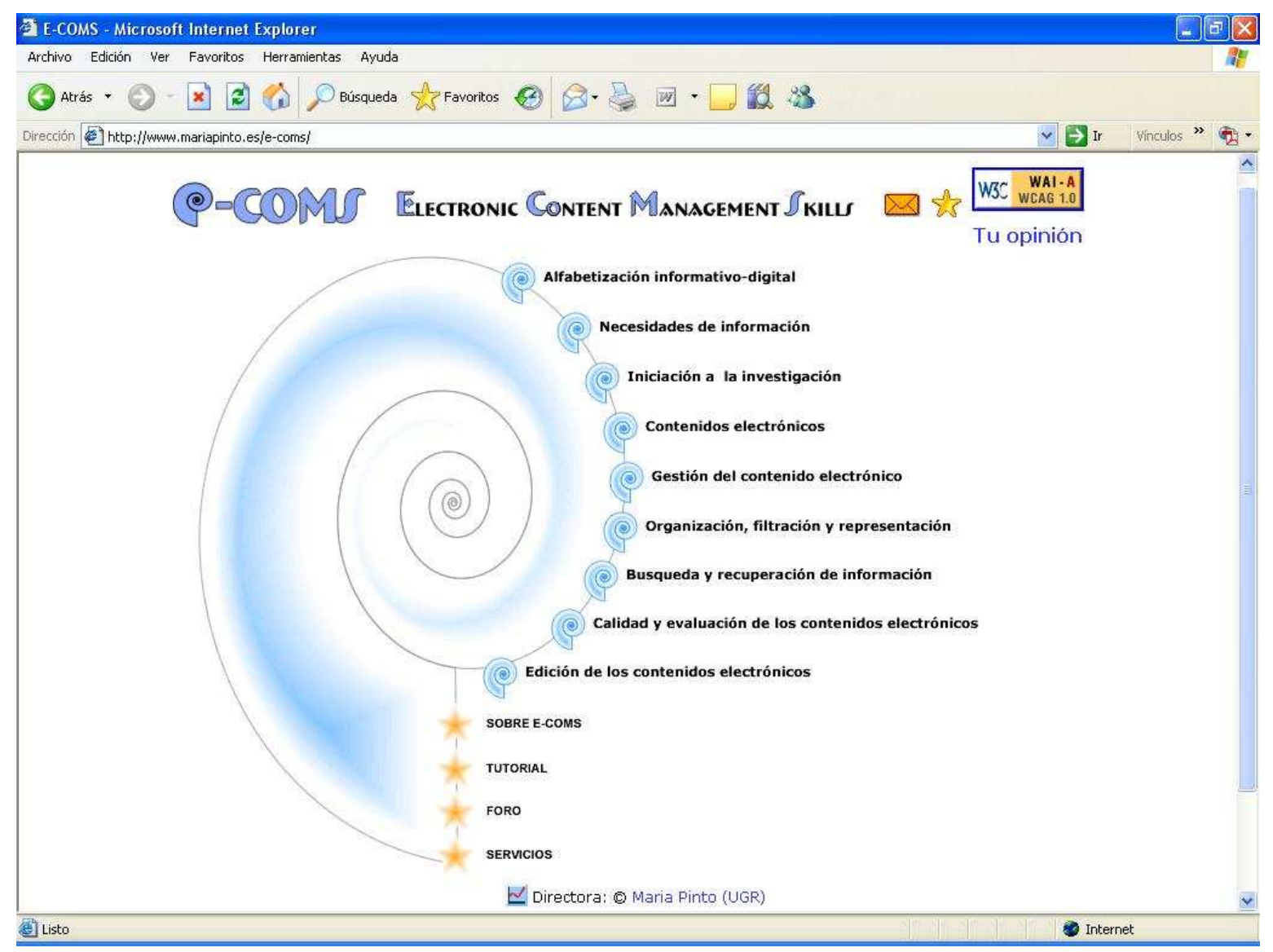

Figure 2. e-COMS homepage

\subsection{Objectives}

The e-COMS portal arose out of a combination of three key elements: the European dimension on higher education and in particular the new targets set by the e-Europe 2005 program that aims to provide students with a series of skills and abilities to manage, analyze and evaluate information; the socioconstructivist approach to education, which plays a significant role in e-learning instruction; and the information literacy paradigm $[3,4,5]$ as a key competency in every student's generic education.

The generic aim of the portal is to provide a conceptual and procedural tutorial focusing on the knowledge and handling of tools for electronic content management and on providing information literacy instruction for students, equipping them with a set of skills and abilities that will prepare them to face the changes in the information and knowledge society. The general aims of the portal are to provide instruction in the following key competencies: cognitive, technological, documentary, research and communicative.

These general aims are specified in the following specific goals:

- $\quad$ to construct an interactive portal for "learning to learn", and to instruct students in information 


\section{literacy;}

- $\quad$ to be a training and information reference portal for library science and documentation and psychopedagogy students, even though the portal was piloted in other technical areas;

- $\quad$ to train students to develop their analytical and summarizing capacities;

- $\quad$ to provide basic techniques in searching for, retrieving and evaluating information: learning how to do;

- $\quad$ to teach how to organize and represent information;

- $\quad$ to teach how to use synchronous and asynchronous communication systems in the process of creating and exchanging knowledge.

\subsection{Methodology}

The platform for developing e-COMS was based on the philosophy of the following models: Big Six [25], FORMIST [26], PLUS [27] and CERISE [28], the latter developed by URFIST (Unite Regionale de Formation a l'Information Scientifique et Technique) teaching staff and librarians and various Parisian universities. In addition, the project evolved from the analysis and assimilation of an extensive list of working documents published by international organizations and prestigious university library associations, including the following: UKOLN [29], ACRL/ALA Information Literacy Standards [3], CAUL Information Literacy Standards [4], AECT, UNESCO World Declaration on Higher Education, the Bologna Declaration [30], CRUE [31], European Commission [1], the Graz Declaration [2] and the e-EUROPE initiative, which particularly emphasizes the organizational changes to higher education grounded in lifelong learning, the development of multidisciplinary or transversal skills, and the acquisition of a basic set of generic skills and competencies for information-digital literacy such as:

conceptual skills: related to the identification of existing knowledge, concept mapping, the development of group techniques for analysis and information sharing etc.;

- $\quad$ technological skills: related to the selection, search, retrieval and access to electronic contents;

- $\quad$ pragmatic skills: related to information analysis, representation, organization and reuse;

- $\quad$ evaluative skills: to foster a critical spirit and the capacity for interaction with information by identifying its authenticity and relevance. 


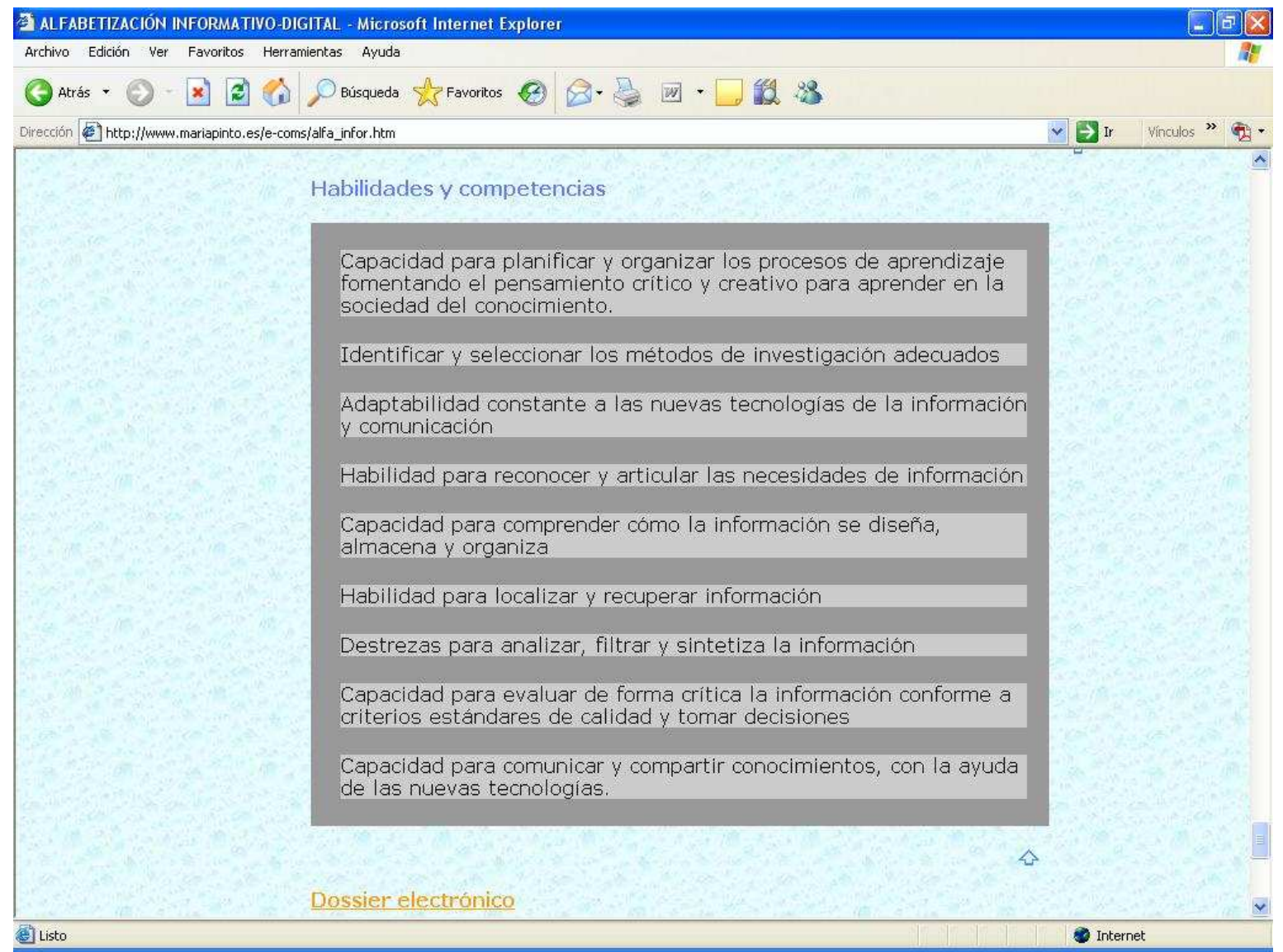

Figure 3. Example of skills

The portal subject content is presented following an intuitive schema based on the elements below:

- Summary.

- $\quad$ Content organized into eight categories.

- $\quad$ Skills and competencies for each category.

- $\quad$ Electronic dossier.

- $\quad$ Bibliographic dossier.

- $\quad$ Tools for consultation, opinion and communication. 


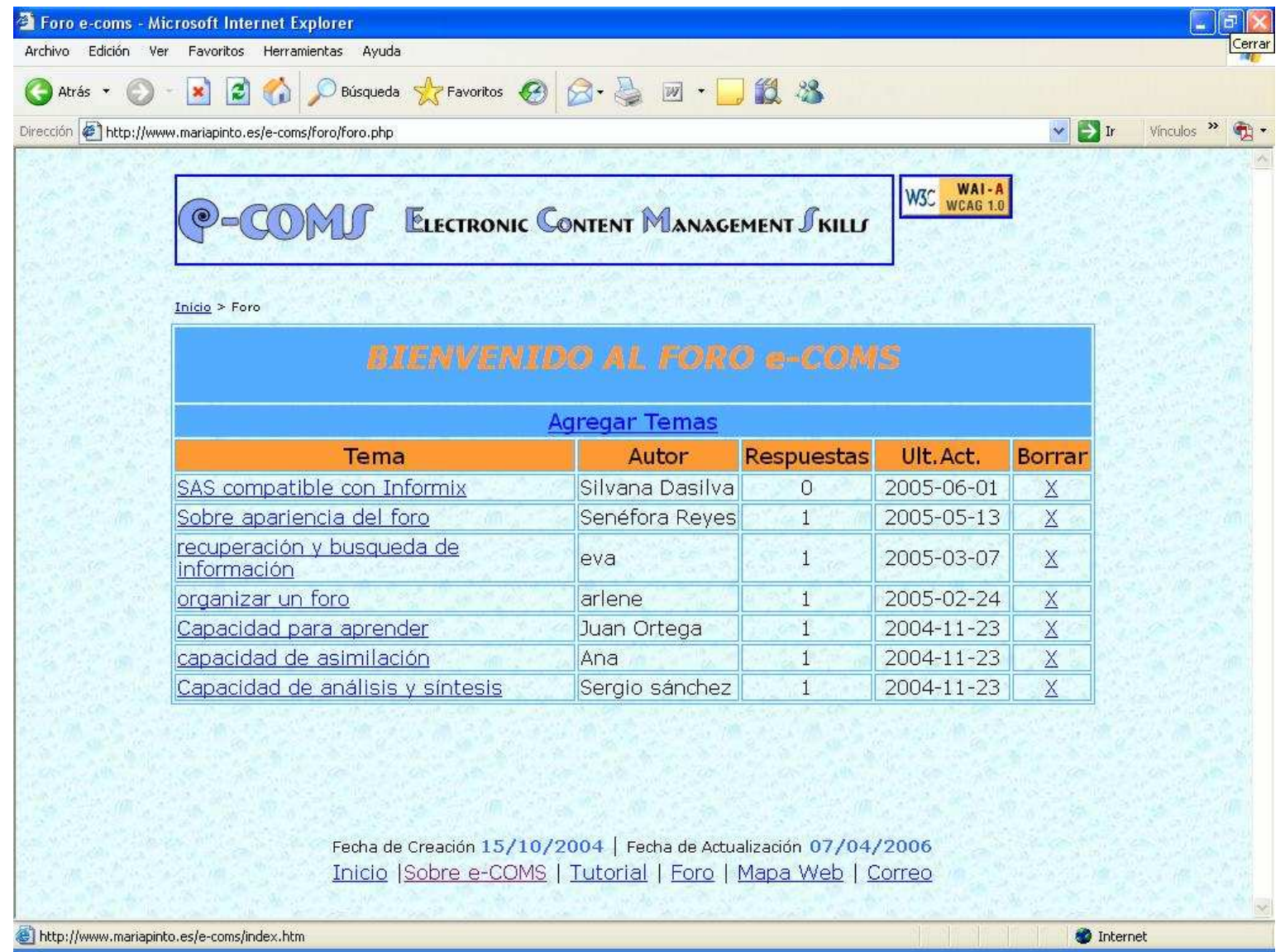

Figure 4. e-COMS forum

The current literature on the essential characteristics of e-learning portals [17, 18, 21, 22] provided references for the following dimensions to be considered in the e-COMS portal:

- Inclusiveness: e-COMS supports the learning of various communities of students, professionals and users.

- Integration: e-COMS has evolved from the present institutional situation in Spanish universities and meets the needs of their members.

- $\quad$ Learner-centeredness: e-COMS provides teaching material and innovative resources with a high level of dynamism and interactivity.

- Accessibility: in e-COMS, resources are identified, organized and represented in ways that make them easy to retrieve, use and reuse.

- Flexibility: e-COMS is an open, elastic portal and as such, allows for new resources to be added, thus responding to the lifelong learning needs of its users.

- Navigability: site architecture and navigation should align with the goals of the site and represent a clear relationship between ideas and concepts. 
- $\quad$ Responsible management: e-COMS provides for user evaluation of the portal through an online questionnaire, so as to be closely aware of its users' opinions and foster best practices.

- $\quad$ Updating: the e-COMS portal is frequently upgraded and extended

- $\quad$ Collaboration: the joint efforts of all members involved, teaching staff, researchers and students, is encouraged.

\subsection{Contents}

The e-COMS portal is hierarchically organized into subject categories and subcategories, starting from its home page. From this page, access is available to the project presentation, credits and author information, and support tools as information search, help in using the site, study support and communication.

Eight blocks of transversal content were established to link in with electronic information management skills.

Information-digital literacy: the concept of information literacy as a way of learning to learn, and the international standards and projects within the university setting are explained.

- Information needs: the concept of information need is explained; awareness of both potential and actual users' needs is essential in order to know their wishes as regards the documentary services they require.

- $\quad$ Initiation in research: the principles of scientific thought, the processes of creation and innovation, and research methods and techniques are examined in depth.

- $\quad$ Electronic content: the concept of electronic content is explained, free of boundaries and integrated in networks, where any user can create, recreate, modify and reuse content.

- $\quad$ Electronic content management: the importance of electronic content management and critical interpretation of the information contained in documents are covered.

- $\quad$ Organization, filtering and representation of information: knowing how to organize, analyze, process, filter and represent electronic content synthetically is becoming increasingly more essential in the electronic environment.

- Information search and retrieval: the concepts of information search and retrieval are introduced, and the student is taught to handle different methods, techniques and tools to guarantee quality retrieval.

- Quality and evaluation of electronic content: the ease and freedom with which content can be published on the Internet means that students need to adopt a set of criteria that will help them to filter electronic content and recognize the quality of the information provided.

- $\quad$ Editing of electronic content: Internet-based editing is now an accessible reality for everyone. Electronic editing projects are often multimedia projects that combine a whole range of supporting media, from text through audio, video, etc, to virtual reality. 


\subsection{Learner usability}

e-COMS is an easy to use, intuitive portal, constructed by means of web language patterns, structured in modular categories and with active, relevant links between its components and concepts, to provide directed, pleasant and personalized navigation. All the necessary strategies have been used for the selection, systemization and structuring of the content, so that students may use it in their lifelong learning. The interface is transparent and does not require excessive user effort [18]. The portal gives fast, easy access to the information the user wants, as it has visible navigable menus [32]. End users are not concerned with the design of the system, the elegance of the retrieval engine or the structure of the data unless these impede the accomplishment of their goals

\section{Conclusions}

As we have explained, social and economic forces are driving the development of higher education. Learning in today's university environment must be meaningful, personal, continuous and social. It must be grounded in the appropriate motivation, in the pre-existing concepts-skills-attitudes mechanism and in those introduced more recently, to combine declarative (knowing) and procedural (know-how) knowledge. Information literacy and transversal documentation instruction are fully integrated in this framework of action, and it is from this position that we have approached the design and implementation of the e-COMS portal, a pioneering initiative in the Spanish language.

The e-COMS design is firmly embedded in a user-centered philosophy [33]. It incorporates user needs and preferences, forms of information access and different levels of knowledge to enable the user to acquire the basic concepts and instruments and the generic skills and abilities on how to create, organize, analyze, filter, represent, evaluate, retrieve and use information, both as a learning process resource and in his or her professional career. The generic content model proposed here is expressed in a language familiar to students that is transmitted through the Internet by means of conventional web and e-learning navigation, retrieval and interaction tools.

The caliber of the e-COMS portal design, particularly its content and organization design, is proven by the number of visitors it received in its first operating year (November 2004-2005), which totaled over 12,000 national and international users, from a variety of academic settings (universities, libraries, professional associations and students) in Spanish speaking countries such as Spain, Argentina, Mexico and Colombia, but also from the United States and other European countries. It is also used by numerous groups of students, young researchers and teaching staff as a complementary resource in information literacy instruction, lending clear support to autonomous ways of working. Results will shortly be available from a qualitative-quantitative study into the portal's visibility and usability, aiming to reveal its impact within the academic education framework. 
[1] Commission of the European Communities, Communication from the commission, the role of the universities in the Europe of Knowledge, Brussels, 5-02-2003, COM (2003) 58 final. Available:

http://europa.eu.int/eur-lex/lex/LexUriServ/site/en/com/2003/com2003_0058en01.pdf (April 14, 2006).

[2] European University Association, Graz Declaration 2003, forward from Berlin: the role of Universities, (2003). Available:

http://www.crue.org/espaeuro/lastdocs/Graz\%20Declaration\%20(EUA)\%20varias\%20lenguas.pdf (April 14, 2006).

[3] American Library Association, Association of College \& Research Libraries, Information Literacy Competency Standards for Higher Education, ALA, ACRL, Chicago, 2005-2006. Available: http://www.ala.org/acrl/ilcomstan.html (April 14, 2006).

[4] Council of Australian University Librarians, "Information Literacy Standards," (Canberra: CAUL, 2001). Available: http://www.caul.edu.au/info-literacy/ (April 14, 2006).

[5] IFLA, Information Literacy Section (2006). Available: http://www.ifla.org/VII/s42/ (April 14, 2006).

[6] UNESCO, Education: the necessary utopia (The Delors report) (1996). Available: http://unesco.org/delors/utopia.htm (December 28, 2005).

[7] Maria Pinto (coord.), "Portal e-COMS: Electronic content management skills," (Tutorial hipertextual sobre alfabetización en información: habilidades para la gestión de los contenidos electrónicos), (2004-2006). Available: http://www.mariapinto.es/e-coms

[8] R. Burnhein, "Information literacy -a core competency," Australian Academic and Research Libraries, 2 (1992):188-196.

[9] N. Dewald, A. Scholz-Crane, A. Booth, \& C. Levine, "Information literacy at a distance: instructional design issues,” The Journal of Academic Librarianship, 26(1) (2000):33-44. 
[10] C. Koh, "Reconsidering services for the postmodern student", Australian Academic \& Research Libraries, 34 (3) (2003): 184-193

[11] A. Jabro, \& J. Corinth, "Crisis in information literacy", Academic exchange quarterly, 9 (2) (2005): 4650 .

[12] Peter F. Drucker, “Managing Oneself”, Harvard Business Review, 77 (1999):65-74.

[13] D.S. Rychen, \& L.H. Salganik, Key Competencies for a Successful Life and a Well-Functioning Society, (Göttingen: Hogrefe \& Huber Publishers, 2003).

[14] OCDE, DeSeCo: Definition and selection of competencies: theoretical and conceptual foundations. (2005). Available: http://www.portal-stat.admin.ch/deseco/index.htm (April 15, 2006).

[15] P. Henry, "E-learning technology, content and service," Education \& Training, 43 (2001): 249-255.

[16] B.H. Khan, “A framework for webbased learning,” TechTrends. 44 (2000): 51.

[17] D. Eisler, “The portal's progress: a gateway for access, information and learning communities", Syllabus 14 (2000):12-18. Available: http://www.buffalo.edu/aboutmyub/pdf/sept00_fea.pdf (November 07, 2005).

[18] Katy Campbell \& Robert Aucoin, "Values-Based Design of Learning Portals as New Academic Spaces", in Designing Portals: Opportunities and Challenges, edited by Ali Jafari and Mark Sheehan (Hershey, PA.: Information Science Publishing, 2003), pp. 162-185.

[19] T. Batson, "Campus Portals and faculty development”, paper presented at Syllabus 2000: New dimensions in Educational Technology Conference, (Boston, November 2000).

[20] M. Looney \& P. Lyman, "Portals in higher education”, EDUCAUSE Review, 35 (4) (2000): 28-36. Online. Available: http://www.educause.edu/apps/er/erm00/articles004/looney.pdf (November 07, 2005).

[21] J. Campbell, "The case for creating a scholars portal to the web: a white paper," Portal: libraries and the academy 1 (2001): 15-21. 
[22] H. Paadre, \& S. King, College of the Holy Cross: Electronic Community and Portals, (White paper retrieved November 29, 2000). Available: http://www.mis2.udel.edu/ja-sig/holycross.doc (November 07, 2005).

[23] REBIUN. Plan Estratégico (2003-2006), 2002. Available:

http://www.crue.org/rebiun/PlanEstrategico.pdf (April 14, 2006).

[24] Ali Jafari, "Educational Portal White Paper", in Designing Portals: Opportunities and Challenges, edited by Ali Jafari and Mark Sheehan (Hershey, PA.: Information Science Publishing, 2003), pp.270-290.

[25] Big Six Skills (1995). Available: http://www.big6.com (April 15, 2006).

[26] Formist (1998). Available: http://formist.enssib.fr/ (April 14, 2006).

[27] Plus (1999). Available: http://www.ltscotland.org.uk/5to14/specialfocus/informationskills/ (April 15, 2006).

[28] Cerise (1999). Available: http://www.ext.upmc.fr/urfist/cerise/index.htm (April 15, 2006).

[29] Ukoln (1997). Available: http://www.ukoln.ac.uk/ (April 15, 2006).

[30] Declaración de Bolonia (1999). Available: http://aect.ed.psu.edu/aectweb/ (April 15, 2006).

[31] CRUE (2000). Available: http://www.crue.org (April 15, 2006).

[32] Gary Marchionini, “Interfaces for end-user information seeking," Journal of the American Society for Information Science 43 (1992):156-163.

[33] C. Maybee, "Undergraduate Perceptions of Information Use: The Basis for Creating User-Centered Student Information Literacy Instruction,” Journal of Academic Librarianship, 32 (2006):79-85. 